\title{
Research Paper: Effect of Two Couple Therapies, Acceptance and Commitment Therapy and Schema Therapy, on Forgiveness and Fear of Intimacy in Conflicting Couples
}

\author{
Fatemeh Fani Sobhani $^{1}$ (D), Shohreh Ghorban Shiroudi ${ }^{* *}$ (D), Anahita Khodabakhshi-Koolaee ${ }^{3}$ (i)
}

1. Department of Counseling, Faculty of Humanities and Social Sciences, Tehran North Branch, Islamic Azad University, Tehran, Iran

2. Department of Psychology, Faculty of Humanities and Social Sciences, Tonekabon Branch, Islamic Azad University, Tonekabon, Iran

3. Department of Psychology and Education Sciences, Faculty of Humanities, Khatam University, Tehran, Iran.

\begin{tabular}{|c|c|}
\hline $\begin{array}{l}\text { Useyour device to tscan } \\
\text { and read the article online }\end{array}$ & dtation Fani Sobhani, F., Ghorban Shiroudi, S., \& Khodabakhshi-Koolaee, A. (2021). The Effect of Two Couple Therapies, \\
\hline 口:3y: & ACT and Schema Therapy, on Forgiveness and Fear of Intimacy in Couples' Conflicts. Journal of Practice in Clinical Psychology, \\
\hline ifting & 9(4), 271-282. https://doi.org/10.32598/jpcp.9.4.746.3 \\
\hline ats & dol'https://doi.org/10.32598/jpcp.9.4.746.3 \\
\hline
\end{tabular}

\section{(1) (5)}

\section{Article info:}

Received: 13 Jul 2021

Accepted: 09 Sep 2021

Available Online: 01 Oct 2021

Keywords:

Acceptance and Commitment Therapy (ACT), Schema therapy, Forgiveness, Intimate relationship, Couple therapy

\section{ABSTRACT}

Objective: This study aimed to compare the effectiveness of Aceptance and Commitment Therapy (ACT) and schema therapy on forgiveness and fear of intimacy in conflicting couples.

Methods: This quasi-experimental study was conducted using a pre-test, post-test design with a control group. The participants were selected from the conflicting couples who were referred to counseling and psychological service centers in districts 1 and 5 of Tehran in 2019. Of the couples who scored high on the Fear-of-Intimacy Scale and obtained a low score on the Interpersonal Forgiveness Inventory, 30 couples (60 people) were selected using convenience sampling and randomly assigned to the schema therapy group (10 couples), the ACT group (10 couples), and the control group (10 couples). Then, the participants in each of the intervention groups attended eight 90-minute therapy sessions based on ACT and Schema therapy techniques. After the interventions, the participants in the three groups completed the questionnaires again and were followed up after three months.

Results: The results showed that both ACT and schema therapy had a significant effect on fear of intimacy and forgiveness. Upon controlling the pre-test score, significant differences were found between the two ACT and schema therapy groups in terms of reconnection and revenge control $(\mathrm{P}<0.01)$, but the two groups were not significantly different in terms of resentment control, realistic perceptions, and fear of intimacy and schema couple therapy was more effective than ACT in controlling conflicting couples' revenge and improving reconnection and this greater effectiveness was still retained in the follow-up phase.

Conclusion: ACT and schema-based couple therapies can be used by psychologists and counselors as effective approaches to increase forgiveness and reduce fear of intimacy in couples. However, schema couple therapy is more effective than ACT in controlling negative emotions and treating them in couples.

\section{* Corresponding Author:}

Shohreh Ghorban Shiroudi, PhD.

Address: Department of Psychology, Faculty of Humanities and Social Sciences, Tonekabon Branch, Islamic Azad University, Tonekabon, Iran Tel: +98 (115) 4271105

E-mail: shohreshiroudi@gmail.com 


\section{Highlights}

- Several factors may disrupt the relationship between couples. These factors are the fear of intimacy and lack of forgiveness.

-The absence of intimacy is significantly associated with depression, low self-esteem, anxiety, and low communication satisfaction in couples.

- This study aimed to compare the effectiveness of two couple therapies, Acceptance and Commitment Therapy (ACT) and schema therapy on forgiveness and fear of intimacy in conflicting couples.

- The results indicated that both ACT and schema couple therapy are effective in reducing fear of intimacy and increasing the forgiveness ability in couples' conflicts. However, Schema couple therapy is more effective than ACT in controlling negative emotions and treating them in couples.

\section{Plain Language Summary}

Couple therapy programs help couples to make their relationships better to have appropriate intimacy. Both Acceptance and Commitment Therapy (ACT) and schema therapy programs help couples to improve their relationship by recognizing their psychological and behavioral problems and reducing the problems and worries of themselves, such as fear of intimacy. These interventions increase the ability to forgive each other. In this research, the authors revealed that the effect of two couple therapies helps couples to reduce their conflicts.

\section{Introduction}

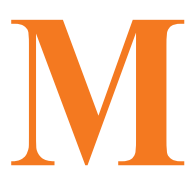

ost people consider marriage to be the most intimate adult relationship, which is the main source of affection and support for them (Jamalnik, Falsafinejad , \& Khodabakhshi-Koolaee, 2020), but several factors may disrupt this relationship and consequently threaten the couple's relationship. One of these factors is the fear of intimacy between couples. Intimacy is one of the basic human needs to maintain mental health and psychological adaptation. The absence of intimacy is significantly associated with depression, low self-esteem, anxiety, and low communication satisfaction (Padgett, Mahoney, Pargament, \& DeMaris, 2019). Intimacy, which includes emotional, physical, sexual, and intimate aspects, can be a source of fear, anxiety, and difficulty in approaching others for some people (Obeid et al., 2019). These people avoid self-disclosure and have difficulty expressing their personal beliefs, intentions, and interests to their best partner (Spokas, Luterek, \& Heimberg, 2009). Thus, fear of intimacy is formed when a person's capability to express intimacy is declined (Khodabakhshi Koolaee, Ahangar, Khozani, \& Hammedy, 2012). The fear of intimacy happens when people are afraid of an experience, such as sharing their deepest thoughts and feelings with others. These people are afraid of being disclosed deeply and share love, feelings, smiles, joy, and even creativity with others (Karakis \& Levant 2012). Fear of intimacy, which affects various emotional, cognitive, and behavioral dimensions of intimacy, severely disrupts interpersonal relationships and public health. When a person has increased fear of intimacy, he/ she has difficulty in establishing and maintaining communication, having positive feelings about relationships, and expressing feelings and emotions, resulting in reduced life satisfaction (Thelen, Vander, Wal, Thomas, \& Harmon, 2000). Research has also shown that intimacy between couples is an important factor in creating lasting marriages, and avoiding intimate relationships can lead to failure in marital life and consequently result in issues, such as marital infidelity (Pananakhonsab, 2019). When couples are afraid of too much intimacy or closeness, they are more likely to suppress or avoid sharing their thoughts and feelings, and this can have negative consequences in their marital relationships. Suppression of positive or negative emotions in interactions with others reduces the sense of understanding and prevents the formation of closer relationships. Fear of intimacy and avoidance of open communication and expression of emotions, due to fear of negative evaluation in marital relationships, has significant consequences in terms of overall satisfaction (Montesi, Conner, Gordon, Fauber, Kim, \& Heimberg, 2013). The potential forces latent in intimacy always equip couples with the tools to resolve conflicts that may arise. Couples need to learn new ways 
of communicating with each other and change the basic assumptions of their relationship with their partner. When couples fail to do so, intimacy and commitment are broken. Thus, the foundations of intimacy in couples should be reformed, which requires analyzing intra-psychological and interpersonal dynamics (Jamalnik et al. 2020).

Another factor that was investigated in the present study and is effective in strengthening marital life is forgiveness. It can increase communication processes to heal family's grievances leading to increased mental health. Enright (2001) defined forgiveness as ignoring others' faults to reach inner peace or improve the relationships with the wrongdoer or to perform value behavior and has the consequences of getting rid of negative feelings towards the wrongdoer, overcoming resentment from evil, and avoiding anger, distance, separation, and revenge against the wrongdoer. Forgiveness, meanwhile, is a reaction that allows a relationship to continue despite mistakes, betrayals, or failures (Fincham \& Beach, 2002). Forgiveness allows for intimacy to be re-established after threats, and couples maintain their stable and longterm relationships (Ehteshamzadeh, Ahadi, Enayati, \& Heidari, 2011). Thus, marital forgiveness eliminates the negative interactions of couples and brings them closer to each other, resulting in satisfaction with marital life and a rational effort to resolve inevitable conflicts, enabling the couples to restore their healthy functioning, and this pattern, in addition to ensuring their mental health, will continue for generations to come (Shirzadi, Khakpour, \& Khodabakhshi-Koolaee, 2021).

Couples therapy is one of the important components of health services and it has been shown that couple therapy is a useful treatment option to reduce marital conflicts (Lebow, Chambers, Christensen, \& Johnson, 2012). One of the several couple therapy techniques used to reinforce couples' relationships is Acceptance and Commitment Therapy (ACT). The purpose of ACT is not to make a direct change in the clients, but to help them to communicate with their experiences in different ways and to be able to be fully involved with a meaningful and value-based life. The goal of this treatment is to increase psychological and behavioral flexibility in areas where experiential avoidance prevails and deprives the individual of basic life. Psychological flexibility increases a person's ability to make practical choices between different competing options available. ACT enables clients to contact the present moment and change or maintain the behavior in the service of valuable and important life goals (Forman \& Herbert, 2009). The two key concepts in this type of treatment are psychological flexibility and experiential avoidance. Psychological flexibility means developing the ability to make practical choices among a large number of competing options, rather than taking or being forced to take an action simply to avoid disturbing thoughts, feelings, and desires. Experiential avoidance occurs when a person does not want to stay in certain private experiences and seeks to correct the form or frequency of these experiences (Nenadić, Lamberth, \& Reiss, 2017). Psychological flexibility in the ACT is accomplished through the six core processes of acceptance, cognitive diffusion, self as context, contacting the present moment, values, and committed action. The main advantage of this treatment technique compared to other psychotherapies is considering the motivational aspects along with the cognitive aspects to make the treatment more effective and lasting. Hayes and Wilson believe that the core message in the ACT is to help clients to accept what is out of their control and make them committed to doing everything in their control (Hayes \& Wilson, 2003). Therapists using ACT-based couple therapy interpret love as a valued practice based on acceptance and commitment. It is easier for couples to talk about ups and downs if the couples act on the values they have married to their spouse. Acting on values also makes couples happier in their relationships. The nature of marital relationships is such that couples face many ups and downs; which indicates why being flexible in a relationship is so important. Psychological flexibility, which is one of the goals of ACT-based couple therapy, helps couples maintain marital intimacy. Psychological flexibility in ACT-based couple therapy refers to the ability to contact the present moment and change or maintain the behavior in the service of valuable and important life goals (Dahl, Stewart, Martell, Kaplan, \& Walser, 2014).

Another effective method of couple therapy that examines the attitudes and experiences of people in their current relationships is schema therapy based on Young's theory. Schema therapy is an integrated therapy that mixes cognitive-behavioral therapy, object relations theory, Gestalt therapy, and attachment theory in a systematic model of therapy (Bach, Lockwood, \& Young, 2018). Schemas are deep and comprehensive patterns formed by memories, emotions, and cognition in childhood and adolescence and continue into adulthood. Schemas are structures that are formed based on reality or experience and mediate individuals' behavioral responses (Nenadić, et al., 2017). In schema therapy, in addition to cognitivebehavioral therapy and the use of experimental techniques with core, experimental techniques, such as imagery work and chair work are used. The goal of this therapy is to use more adaptive coping styles instead of incompatible coping styles so that the patients can satisfy 
their emotional needs (Calvete, Orue, \& Hankin, 2013). Maladaptive schemas (or negative core beliefs) refer to a dysfunctional cognitive framework for observing oneself and others that is initially formed in response to childhood maladaptive events and continually spreads throughout one's life. Through schema therapy, the gaps and problems in couples' lives are recognized and they are helped to learn how to overcome them and succeed in creating unity and totality in their married life. These two features are attained by recognizing schemas and questioning their validity and breaking behavioral patterns (SimeoneDiFrancesco, Roediger, \& Stevens, 2015).

Although among the third-wave cognitive-behavioral therapies, ACT is one of the first methods of thoughtful acceptance in early development based on the ideas of cognitive-behavioral therapy, this treatment claims that cognitive-behavioral therapy was a right problem but a wrong solution. This approach aimed to find a solution that is aligned with the best behavioral tradition and develop a growing body of behavioral principles that cover a useful and strong behavioral description of human language and cognition (Harris, 2009). Instead of changing cognitions and beliefs, these therapies seek to increase the person's psychological connection with his/her thoughts and feelings. The main goal in the ACT is to create psychological flexibility, i.e. creating the ability to make practical choices among a large number of competing options, rather than taking or being forced to take an action simply to avoid disturbing thoughts, feelings, and desires (Forman, \& Herbert, 2009). ACT conceptualizes marital problems differently. Accordingly, the maintenance and spread of distress, conflicts, and emotional distance between couples stem from a combination of control and experiential avoidance strategies in the marital relationship. Taking thoughts as reality, negative evaluations, and acting on them maintain a cycle of negative communication between couples (Peterson, Eifert, Feingold, \& Davidson, 2009). ACT has been effective in various areas, such as depression (Kanter, Baruch, \& Gaynor, 2006), psychosis (Bach \& Hayes, 2002), and burnout (Bond \& Bunce, 2003). Furthermore, Peterson et al. (2009) reported that ACT increased the adjustment of disturbed couples. Given the differences between schema therapy and ACT and their effectiveness in solving couples' problems and considering the role of intimacy and forgiveness in the stability of marriage and marital satisfaction of couples, conducting comparative studies can further clarify the strengths and weaknesses of these two therapeutic approaches. Thus, the present study was done to explore the effectiveness of an integrated ACT and schema therapy in improving forgiveness and reducing fear of intimacy in conflicting couples.

\section{Materials and Methods}

\section{Research design}

This study was an applied study in terms of its objectives and was conducted using a quasi-experimental research design with pre-test and post-test, control group, and random allocation. The research population included all couples with marital conflicts who referred to counseling and psychological service centers licensed by the Iranian Psychological and Counseling Organization and the Welfare Organization of districts 1 to 5 of Tehran in 2019. Given the research design and taking into account the possibility of dropout, a total of 60 persons (30 couples) were selected as the participants among the couples who scored high on the Fear-of-Intimacy Scale and obtained low scores on the Interpersonal Forgiveness Inventory using convenience sampling. No drop of the participants was reported during the research stages. The selected persons were randomly assigned to the schema therapy group (10 couples), the ACT group (10 couples), and the control group (10 couples). The participants were a total of 60 couples who were selected via simple random sampling and randomly assigned to two groups (Schema and ACT intervention groups and the control group), each with 20 participants. The sample size was calculated for each group equal to 20 based on the effect size of 0.25 , alpha of 0.05 , and test power of 0.80 . The criteria for enrollment in the study were informed consent to participate in the study, high score of fear of intimacy and a low score of forgiveness, couples who lived together for one to 10 years, conflict at one of the levels $(1,2$, and 3 ) (no legal and judicial action taken for separation), having at least a diploma, no psychiatric disorders that required medication or psychotherapy approved by a psychiatric and clinical psychologist by a structural interview in the clinic, and no addiction of each couple to drugs and stimulants. Besides, the exclusion criteria were unwillingness to continue participating in the study, taking legal action for divorce, and simultaneous participation in other psychological programs.

\section{Instruments}

Fear-of-intimacy Scale (FIS): This 35-item self-report tool was developed by Descutner and Thelen (1991) to measure individuals' anxiety about close romantic relationships. The items are scored on a five-point Likert scale ranging from 1 (not at all characteristic of me) to 5 (extremely characteristic of me), with a total score ranging from 35 to 175 . This scale has two subscales: items 1 to 30 are related to the person who would be in a close relationship with the respondent and items 31 
to 35 are related to the respondents' past relationships. A higher score that is close to 175 and shows that the person fears intimacy in their relationships with others and lower scores close to 35 indicate that the person is not concerned about intimacy in their relationships with others. The total score on the two subscales is calculated as the sum of the scores of the individual's items. The total score on each subscale is measured based on the number of items in the subscale. Descutner and Thelen (1991) used discriminant and convergent validity indices to assess the validity of this scale. To do this, they used the Gerard Self-Disclosure Scale, the Miller Social Intimacy Scale, the UCLA Loneliness Scale, the Need for Cognition Scale (NFC-short), and the Intimate Friendship Scale (IFS), and reported optimal values for both discriminant and convergent validity indices (Thelen et al., 2000). They also assessed the reliability of the scale and showed that FIS has high internal consistency (0.93) and high test-retest reliability $(\mathrm{r}=0.89)$. Khodabakhshi Koolaee et al. (2013) assessed the psychometric properties of the scale. Factor analysis revealed two factors in 35 items: factor 1 showed the fear of intimacy in one's relationships with the spouse and factor 2 was the fear of intimacy in relationships with others. The internal consistency of the whole scale was estimated to be 0.84 (Khodabakhshi Koolaee \& Hashemi Asl, 2016).

Interpersonal Forgiveness Inventory (IFI-25): The IFI-25 was developed by Ehteshamzadeh et al. (2010) to measure interpersonal forgiveness. They validated the inventory in a pilot study on a sample of undergraduate students in Ahvaz universities in the academic year 20082009. The reliability value calculated for the whole inventory through Cronbach's alpha was 0.80 . The corresponding values for the subscales of the inventory, including reconnection and revenge control, resentment control, and realistic perceptions were $0.77,0.66$, and 0.57 , respectively. Moreover, the reliability values calculated using the test-retest method for the whole inventory and the three subscales (reconnection and revenge control, resentment control, and realistic perceptions) were $0.71,0.71$, 0.68 , and 0.58 , respectively. The 25 items in the inventory are scored using a Likert scale and a total score is obtained for the whole inventory and three scores for the three individual subscales. Items 19, 20, 21, 22, 23, 24, 25 , are scored reversely ( $1=$ totally disagree, $2=$ disagree, $3=$ agree, and $4=$ totally agree). The total score on the inventory ranges from 25 to 100, with higher scores indicating a greater ability to forgive others' mistakes. The first subscale (reconnection and revenge control) contains 12 items with the total score ranging from 12 to 48 , with a higher score indicating a greater ability to reestablish relationships with the wrongdoer and a lower score showing a desire for taking revenge for the mistakes committed by others. The second subscale, resentment control, contains six items with a total score ranging from 6 to 24, with a higher score indicating the ability to better control resentment and less rumination about being a victim. Finally, the third subscale (realistic perceptions) contains seven items. The total score on the subscale ranges from 7 to 28 , with higher scores indicating a greater ability to understand human characteristics and conditions leading to mistakes (Ehteshamzadeh et al., 2011).

\section{Procedure}

To comply with the ethical principles, the treatment sessions were also held for the members of the control group at the end of the study. In this article, all ethical principles were taken into account. The participants were informed of the research procedure and signed an informed consent form. They were also ensured that their information would be confidential. Furthermore, they were allowed to leave the study at any time and, if they wished, the results of the research would be made available to them. The collected data were analyzed using Analysis of Covariance (ANCOVA) by SPSS software, v. 22.

A summary of the content of the intervention sessions

Schema therapy was conducted in eight sessions each lasting 120 minutes based on the instructions in the book Schema Therapy with Couples: A Practitioner's Guide to Healing Relationships (Simeone-DiFrancesco et al., 2015) as shown in Table 1.

The participants in the second intervention group attended eight ACT sessions each lasting 120 minutes (Gehart, 2012; Peterson et al., 2009) as displayed in Table 2.

\section{Results}

The study participants' Mean \pm SD age in the three groups was $38.53 \pm 2.85$ years and their age ranged from 32 to 45 years. Also, $72 \%$ of them had a diploma or higher degree and another $28 \%$ had a master's degree.

Table 3 shows the descriptive statistics for the mean scores of forgiveness and fear of intimacy for the three groups in the pre-test, post-test, and follow-up stages after three months.

The null hypothesis for the normality of the distribution of the groups' scores on forgiveness and fear of intimacy was confirmed. Therefore, the assumption of normal distribution of the pre-test and post-test scores for the intervention and control groups was confirmed $(\mathrm{P}<0.05)$. 
Table 1. The instructional content of the schema therapy sessions

\begin{tabular}{|c|c|}
\hline Sessions & Instructions \\
\hline First & $\begin{array}{l}\text { Establishing communication and empathy, introducing the therapist and the couples, stating the group rules and as- } \\
\text { sessing the couples' suitability for schema therapy, taking the pre-test, completing the Young Early Maladaptive Schema } \\
\text { Questionnaire (YEMSQ) by the couples to identify their schemas and search for the root of their problems in the past }\end{array}$ \\
\hline Second & $\begin{array}{l}\text { Introducing the concepts of schema therapy, types of schemas, attitudes, establishing a link between the current prob- } \\
\text { lem and schemas, making the couples familiar with the causes of schemas, examining the roots of schemas, and identi- } \\
\text { fying the first effective experiences and parenting styles of the couples, unsatisfied needs, and their emotional mood }\end{array}$ \\
\hline Third & $\begin{array}{l}\text { Conceptualization of the problem by the couples and ineffective responses and encounters, giving feedback, and provid- } \\
\text { ing assignments to reconstruct the schemas }\end{array}$ \\
\hline Fourth & $\begin{array}{l}\text { Couples evaluating themselves and identifying and discrediting their beliefs by the therapist, use primary and cognitive } \\
\text { schema therapy strategies, giving feedback, and providing assignments to reconstruct the schemas }\end{array}$ \\
\hline Fifth & $\begin{array}{l}\text { Using cognitive schema therapy strategies flexibly to examine the confirming and rejecting evidence, familiarizing one- } \\
\text { self with the concept of core negative beliefs and dysfunctional cognitions to reconstruct the early maladaptive schemas }\end{array}$ \\
\hline Sixth & $\begin{array}{l}\text { Schema therapy emotional strategies aimed at getting the members to know blocked emotions, achieving repressed } \\
\text { memories, changing and improving the emotional balance of the early institutionalized maladaptive schemas }\end{array}$ \\
\hline Seventh & $\begin{array}{l}\text { Interpersonal skills and training techniques to break behavioral patterns to increase motivation and change in behavior } \\
\text { and lifestyles to replace more adaptive and newer behavioral patterns instead of inefficient coping responses along with } \\
\text { assignments }\end{array}$ \\
\hline Eighth & $\begin{array}{l}\text { Investigating the relationship between selecting a type of relationship with the spouse and the persistence of schemas } \\
\text { by couples to get rid of past self-harming patterns, replacing unhealthy and dysfunctional behaviors with healthy and } \\
\text { effective behaviors, summing up the discussions, and taking the post-test }\end{array}$ \\
\hline
\end{tabular}

To run the Multivariate Analysis of Covariance (MANCOVA), the condition of multivariate normality must be met, and since SPSS software does not have a test to determine the multivariate normality, it is assumed that if the distribution of scores for each variable is normal, then, the condition of multivariate normality is also established. Since the distribution of scores for the research variables in the pre-test and post-test stages in the

Table 2. The instructional content of the ACT sessions

\begin{tabular}{|c|c|}
\hline Sessions & Instructions \\
\hline First & $\begin{array}{l}\text { Objective: Introducing the group members, taking the pre-test, discussion of behavioral limits, stating the rules, } \\
\text { principles, and conventions governing counseling the sessions, obtaining informed consent from the group members } \\
\text { to perform the treatment process } \\
\text { Assignment: Identifying the past dysfunctional systems }\end{array}$ \\
\hline Second & $\begin{array}{l}\text { Objective: Introducing the concepts of ACT-based couple therapy, including psychological flexibility, psychological } \\
\text { acceptance, psychological awareness, cognitive separation, self-visualization, personal story, clarification of values, } \\
\text { and committed action. } \\
\text { Assignment: Writing down and listing negative experiences and dysfunctional control of thoughts and feelings }\end{array}$ \\
\hline Third & $\begin{array}{l}\text { Objective: Creative helplessness, exploring the world inside and out, and understanding that control is the problem, } \\
\text { not the solution } \\
\text { Assignment: Recording daily experience and desires }\end{array}$ \\
\hline Fourth & $\begin{array}{l}\text { Objective: Identifying and specifying the couples' values, practices, and barriers } \\
\text { Assignment: Practicing mindfulness and preparing a list of the couple's values }\end{array}$ \\
\hline Fifth & $\begin{array}{l}\text { Objective: To show the importance of values and to explain to the member how values and their understanding } \\
\text { make "desire/acceptance" valuable. } \\
\text { Assignment: Determining the couples' values using metaphors }\end{array}$ \\
\hline Sixth & $\begin{array}{l}\text { Objective: Analyzing fusion and diffusion } \\
\text { Assignment: Doing exercises for diffusion using metaphors }\end{array}$ \\
\hline Seventh & $\begin{array}{l}\text { Objective: Explaining the concepts of role and context, seeing the self as a context, and emphasizing the here and } \\
\text { now } \\
\text { Assignment: Contacting the present moment }\end{array}$ \\
\hline Eighth & $\begin{array}{l}\text { Objective: Evaluating the committed action } \\
\text { Assignment: Identifying behavioral plans in accordance with values and being committed to values } \\
\text { Sixth side (committed action): Understanding the nature of desire and commitment, determining patterns of action } \\
\text { in line with the values, doing exercise (rope bridge, train, ship, and safe beach), summarizing the training sessions, } \\
\text { getting feedback, and finally taking the post-test }\end{array}$ \\
\hline
\end{tabular}


Table 3. The descriptive statistics for the mean scores of forgiveness and fear of intimacy for the three groups

\begin{tabular}{|c|c|c|c|c|c|}
\hline \multirow{2}{*}{ Variable } & \multirow{2}{*}{ Subscale } & \multirow{2}{*}{$\begin{array}{l}\text { Measurement } \\
\text { Stage }\end{array}$} & \multicolumn{3}{|c|}{ Mean $\pm S D$} \\
\hline & & & ACT & Schema Therapy & Control \\
\hline \multirow{9}{*}{ Forgiveness } & \multirow{3}{*}{$\begin{array}{l}\text { Reconnection } \\
\text { and revenge } \\
\text { control }\end{array}$} & Pre-test & $20.56 \pm 3.66$ & $19.00 \pm 2.51$ & $22.40 \pm 2.93$ \\
\hline & & Post-test & $24.50 \pm 4.68$ & $26.40 \pm 1.54$ & $21.60 \pm 2.62$ \\
\hline & & Follow-up & $24.15 \pm 4.55$ & $26.20 \pm 1.91$ & $21.80 \pm 2.86$ \\
\hline & \multirow{3}{*}{$\begin{array}{l}\text { Resentment } \\
\text { control }\end{array}$} & Pre-test & $10.90 \pm 3.06$ & $11.05 \pm 3.44$ & $10.80 \pm 2.82$ \\
\hline & & Post-test & $14.95 \pm 3.66$ & $16.00 \pm 3.01$ & $9.70 \pm 2.70$ \\
\hline & & Follow-up & $13.90 \pm 3.61$ & $12.25 \pm 3.23$ & $10.85 \pm 3.44$ \\
\hline & \multirow{3}{*}{$\begin{array}{l}\text { Realistic percep- } \\
\text { tions }\end{array}$} & Pre-test & $12.95 \pm 3.07$ & $12.10 \pm 2.83$ & $12.60 \pm 3.20$ \\
\hline & & Post-test & $16.90 \pm 3.99$ & $16.80 \pm 3.00$ & $13.45 \pm 2.89$ \\
\hline & & Follow-up & $16.50 \pm 3.07$ & $17.25 \pm 2.75$ & $12.85 \pm 2.54$ \\
\hline \multirow{3}{*}{\multicolumn{2}{|c|}{ Fear of intimacy }} & Pre-test & $98.40 \pm 8.93$ & $102.30 \pm 14.23$ & $96.55 \pm 8.43$ \\
\hline & & Post-test & $89.15 \pm 9.06$ & $90.30 \pm 8.50$ & $99.95 \pm 8.93$ \\
\hline & & Follow-up & $87.90 \pm 9.27$ & $89.90 \pm 6.10$ & $95.60 \pm 7.21$ \\
\hline
\end{tabular}

intervention and control groups was normal, the assumption of multivariate normality was established.

Table 4 shows the results of MANCOVA to compare the ACT and schema therapy groups in terms of forgiveness (reconnection and revenge control, resentment control, and realistic perceptions) and fear of intimacy on the post-test:

As shown in Table 4, after controlling the pre-test effects, the significance levels of all tests indicate that at least one of the dependent variables (forgiveness and fear of intimacy) was significantly different between the ACT and schema therapy groups $(\mathrm{P}<0.01)$, implying that, upon controlling the pre-test score, there was a difference between the two groups in terms of their post-test scores. This shows a significant difference in the effectiveness of the interventions in at least one of the dependent variables. To find out which variable or variables differs between the two intervention groups, the difference between the ACT and schema therapy groups in terms of the two variables of forgiveness and fear of intimacy was determined using analysis of MANCOVA as shown in Table 5.

As can be seen in Table 5, upon controlling the pretest scores, there was a significant difference between the ACT and schema therapy groups in terms of reconnection and revenge control $(\mathrm{P}<0.01)$. However, there was no significant difference between the two groups in terms of resentment control, realistic perceptions, and fear of intimacy $(\mathrm{P}>0.05)$

Table 4. The results of MANCOVA for forgiveness and fear of intimacy in the two groups

\begin{tabular}{|c|c|c|c|c|c|c|}
\hline Test & Statistic & $\mathbf{F}$ & Hypothesis df & Error df & Sig. & $\begin{array}{c}\text { Eta } \\
\text { Squared }\end{array}$ \\
\hline Pillai's trace test & 0.35 & 4.21 & 4 & 31 & 0.008 & 0.88 \\
\hline Wilks' lambda test & 0.65 & 4.21 & 4 & 31 & 0.008 & 0.88 \\
\hline Hotelling's trace test & 0.54 & 4.21 & 4 & 31 & 0.008 & 0.88 \\
\hline Roy's largest root & 0.54 & 4.21 & 4 & 31 & 0.008 & 0.88 \\
\hline
\end{tabular}


Table 5. The results of MANCOVA on the post-test scores of the two groups

\begin{tabular}{lccccccccc}
\hline & Variable & $\begin{array}{c}\text { Sum of } \\
\text { Squares }\end{array}$ & df & $\begin{array}{c}\text { Mean } \\
\text { Square }\end{array}$ & F & Sig. & $\begin{array}{c}\text { Eta } \\
\text { (Effect Size) }\end{array}$ & Power \\
\hline \multirow{2}{*}{ Forgiveness } & Reconnection and revenge control & 88.66 & 1 & 88.66 & 11.19 & 0.002 & 0.25 & 0.90 \\
& Resentment control & 16.21 & 1 & 16.21 & 2.05 & 0.162 & 0.06 & 0.29 \\
& $\quad$ Realistic perceptions & 10.06 & 1 & 10.06 & 1.34 & 0.255 & 0.04 & 0.20 \\
& Fear of intimacy & 9.47 & 1 & 9.47 & 0.24 & 0.626 & 0.01 & 0.08 \\
\hline
\end{tabular}

Table 6. The results of MANCOVA for forgiveness and fear of intimacy in the two groups

\begin{tabular}{ccccccc}
\hline Test & Statistic & F-value & Hypothesis df & Error df & Sig. & Eta Squared \\
\hline Pillai's trace test & 0.35 & 4.26 & 4 & 31 & 0.007 & 0.88 \\
\hline Wilks' lambda test & 0.65 & 4.26 & 4 & 31 & 0.007 & 0.88 \\
\hline Hotelling's trace test & 0.55 & 4.26 & 4 & 31 & 0.007 & 0.88 \\
\hline Roy's largest root & 0.55 & 4.26 & 4 & 31 & 0.007 & 0.88 \\
\hline
\end{tabular}

To explain the intergroup differences in terms of reconnection and revenge control, the mean scores of the two groups in terms of reconnection and revenge control were compared. A comparison of the pre-test score (20.65) and post-test score (24.50) for reconnection and revenge control in the conflicting couples in the ACT group shows that the mean difference in their pre-test and post-test scores was about 4. However, the mean difference in the pre-test score (19.00) and post-test score (26.40) for reconnection and revenge control in the schema therapy group was about 7 , showing that schema therapy was more effective than ACT in improving reconnection and controlling revenge in the conflicting couples.

Table 6 presents the results of MANCOVA to compare the ACT and schema therapy groups in terms of forgiveness (reconnection and revenge control, resentment con- trol, and realistic perceptions) and fear of intimacy in the follow-up phase after three months.

The data in Table 6 suggest that after controlling the pre-test effects, the significance levels of all tests indicated that at least one of the dependent variables (forgiveness and fear of intimacy) was significantly different between the ACT and schema therapy groups $(\mathrm{P}<0.001)$. Table 7 shows the results of MANCOVA to compare the two groups in terms of forgiveness and fear of intimacy in the follow-up phase.

As can be seen in Table 7, upon controlling the pretest scores, there was a significant difference between the ACT and schema therapy groups in terms of reconnection, revenge control, and realistic perceptions in the follow-up phase $(\mathrm{P}<0.05)$. However, there was no sig-

Table 7. The results of MANCOVA by controlling pre-test scores

\begin{tabular}{ccccccccc}
\hline & Variable & $\begin{array}{c}\text { Sum of } \\
\text { Squares }\end{array}$ & df & $\begin{array}{c}\text { Mean } \\
\text { Square }\end{array}$ & F & Sig. & $\begin{array}{c}\text { Eta } \\
\text { (Effect Size) }\end{array}$ & Power \\
\hline \multirow{2}{*}{$\begin{array}{c}\text { Reconnection and re- } \\
\text { venge control }\end{array}$} & 91.85 & 1 & 91.85 & 10.51 & 0.003 & 0.24 & 0.89 \\
& $\begin{array}{l}\text { Resentment control } \\
\text { Realistic perceptions }\end{array}$ & 17.61 & 1 & 17.61 & 2.00 & 0.168 & 0.06 & 0.28 \\
& 29.68 & 1 & 29.68 & 4.95 & 0.033 & 0.13 & 0.58 \\
\hline & 2.32 & 1 & 2.32 & 0.06 & 0.816 & 0.00 & 0.06 \\
\hline
\end{tabular}


nificant difference between the two groups in terms of resentment control and fear of intimacy $(\mathrm{P}>0.05)$. These data indicate that schema therapy was more effective than ACT in retaining the positive effects of the intervention on reconnection and revenge control in the conflicting couples in the follow-up phase.

\section{Discussion}

The results of the present study showed that both ACT and schema therapy had a significant effect on fear of intimacy and forgiveness in conflicting couples. Furthermore, upon controlling the pre-test effect, there were significant differences between the two intervention groups in terms of reconnection and revenge control, but there was no significant difference between the two groups in terms of resentment control, realistic perceptions, and fear of intimacy. It was also found that schema therapy was more effective than ACT in improving reconnection and controlling revenge in the conflicting couples. Moreover, schema therapy was more effective than ACT in retaining the positive effects of the intervention on reconnection and revenge control in the conflicting couples in the follow-up phase. Peterson et al. (2009) found that mindfulness exercises helped conflicting couples become aware of their negative reactions. It also helped them to use consistent and effective strategies in their relationships. Overall, their findings suggested that ACT is effective in increasing couples' marital adjustment and satisfaction and reducing their interpersonal and psychological problems Peterson et al. (2009). In another study, Roediger et al. (2020) showed that the use of schema therapy for couples could be effective in developing a positive image of the partners and a feeling of closeness. Moreover, schema therapy techniques could have stronger effects on the felt closeness and mood of both partners Roediger et al. (2020).

Schema-based couple therapy can be effective in increasing forgiveness. Accordingly, it can be argued that couples who had maladaptive schemas could not ignore the mistakes committed by them and their partners as they failed to consider the special living conditions, paid no attention to their partner's problems and did not empathize with their partner's feelings. Thus, the main goal of schema therapy is to modify a person's maladaptive schemas, thereby helping them to adapt to new experiences that do not endorse the original schema and to develop more adaptive coping behaviors (SimeoneDiFrancesco et al., 2015).

To this end, during the schema therapy sessions, the couples were helped to adjust their maladaptive schemas, and this led to higher levels of understanding, empathy, and forgiveness in them. Concerning the ef- fectiveness of schema therapy on the fear of intimacy, it can be argued that negative childhood experiences create early maladaptive schemas in some individuals that affect the way they think, feel, and behave in later romantic relationships, affecting other aspects of their lives. Körük showed that the early maladaptive schemas and adult attachment styles could predict the psychological tendencies in intimate relationships among couples before marriage. It seems that couples selected mates according to their attachment styles and early maladaptive schemas (Körük, 2017).

It seems that the most important issues in schema therapy are related to rejection and exclusion schemas because people with maladaptive schemas in this area have difficulty communicating directly with other people. To explain the mechanism of action for these schemas, it can be argued that the ability to establish intimate relationships requires the formation of a sense of security, acceptance, and trust in childhood. Thus, people who have difficulty developing a sense of security in childhood will be more likely to avoid intimate relationships for fear of rejection. Furthermore, to account for the mechanism of action of the schemas of self-control and defectiveness in fear of intimacy, it can be suggested that people with these maladaptive schemas face problems mainly due to a lack of necessary skills to establish intimate relationships, which leads to confusion and inability to express feelings and weakness in intimate communication skills. In addition, individuals with obedience schema seek to suppress personal desires and preferences to gain approval and attention from others. Thus, they are more likely to avoid intimacy, which requires restraint in expressing emotions. Emotional inhibition in shaping the fear of intimacy also probably has a mechanism that is similar to obedience, with the difference that one avoids positive emotions and impulses to avoid being rejected by others, feeling ashamed, and losing control of personal impulses.

Individuals with maladaptive schemas in the area of impaired limits are likely to lose the ability to establish intimate relationships due to the development of behaviors that are contrary to intimacy and emotional closeness, and thus the mechanism of cognitive dissonance perpetuates their schemas. Accordingly, schema-based couple therapy in the present study reduced the couple's fear of intimacy in the marital relationship by focusing on the couple's maladaptive schemas and treating them. The present study also confirmed the effectiveness of ACT on the forgiveness of conflicting couples. Thus, it can be argued that a lack of forgiveness in marital relationships can be developed due to people's unawareness of their inner experiences, avoiding unpleasant inner experiences, 
and avoiding behaviors and actions that are important and valuable to the person. Furthermore, individuals' low or incorrect awareness of their inner experiences reduces their ability to functionally use their emotional responses and prevents them from behaving appropriately. Thus, ACT focuses on developing acceptance, concentration, commitment, and behavior change processes to create psychological flexibility (Atkinson \& Perris, 2020).

Furthermore, instead of focusing on eliminating their maladaptive schemas, the couples in this stu dy were helped to accept their controlled cognitions and to free themselves from the control of the verbal $r$ ules that caused their problems. They were also assisted to give up their marital conflicts. The lack of forgiveness can be developed because of the relationship that couples have with their emotions. They made critical judgments about their unpleasant experiences and tried to avoid them, but during the intervention sessions, were taught to more self-consciously deal with personal life experiences and avoid critically judging their partners. They were also trained to complement each other through acceptance exercises. In addition, instructions on behavioral commitment, diffusion and acceptance techniques, and detailed discussions of the individual's values and goals and the need to set personal goals, and the chess metaphor all led to increased forgiveness in the couples. Moreover, the main reason for focusing on the participants' inner thoughts was to help them to experience worrying thoughts as mere thoughts, to become aware of the ineffective nature of one's present plans, and to manage things that were important in a person's life right now in line with their values, instead of reacting to those worrying thoughts. All of these interventions were influential in improving the couples' forgiveness (Najjari, Khodabakhshi Koolaee, \& Falsafinejadm, 2016).

Besides, ACT teaches couples to get closer to unwanted inner thoughts and feelings and physical states related to these dynamics. Approaching thoughts and feelings related to prior avoidance and action to conform to relational values enable couples to communicate more intimately and flexibly with each other. Furthermore, ACTbased couple therapy focuses on the factors that cause psychological inflexibility (such as mental barriers, expectations, vague values, disconnecting from the present, and trying to avoid them) and their remedy, i.e. six processes of psychological flexibility (liberation from the mind, weakening expectations rather than eliminating them, clear values, unification with the partner, and acceptance of suffering), affecting the growth of marital intimacy and its dimensions. The use of metaphors in ACT-based couple therapy helps couples achieve diffu- sion and not get stuck in their mental productions. Moreover, the use of cognitive diffusion techniques helped to bridge the gap between thoughts arising from maladaptive patterns, as these thoughts led couples to familiar avoidance behaviors and forced them to take actions that resulted in confusion, conflicts, separation of couples, and the growth of non-intimate relationships. Cognitive diffusion helped the couples to break away from thoughts induced by old maladaptive patterns, and these thoughts did not interfere with value-oriented activities (McKay, Lev, \& Skeen, 2012).

However, schema couple therapy was more efficacy than ACT in controlling negative emotions and treating them in couples. Early maladaptive schemas are formed by attachment styles and childhood experiences in persons. In other words, schema couple therapy helps the attachment injuries in couple's relationships. It seems that for deeper emotional and affective problems in couples, schema therapy is a better choice for family and marriage counselors and psychotherapists. Given the effectiveness of schema therapy intervention on improving the fear of intimacy and increasing forgiveness in conflicting couples, these techniques can be employed in medical-educational centers and counseling and psychology clinics.

\section{Conclusion}

The present study showed that ACT and schema therapy both had a significant effect on fear of intimacy and forgiveness in conflicting couples. However, schema therapy was found to be more effective than ACT in increasing reconnection and controlling couples' revenge. The results also suggested that the effectiveness of schema therapy in increasing reconnection and controlling the revenge of conflicting couples was more continuous and stable compared to ACT in the follow-up phase. Finally, although both therapies are effective, schema therapy seems to be more efficient than ACT for coping with emotional problems and negative emotions in couples.

One of the limitations of this study is that its findings can only be generalized to clients who met the inclusion criteria for this study and are not applicable to people who are different in terms of demographic characteristics and inclusion criteria. Another limitation of this study could be the impossibility of performing the second follow-up test due to time constraints; thus, measuring the stability of the intervention at different time intervals was not possible. 


\section{Ethical Considerations}

\section{Compliance with ethical guidelines}

The study was approved by the Ethics Committee of the Tehran North Branch, Islamic Azad University (Code: IR.IAU.TNB.REC.1399.045).

Funding

The study was extracted from the $\mathrm{PhD}$. dissertation of the first author at the Department of Counseling, Faculty of Humanities and Social Sciences, Tehran North Branch, Islamic Azad University, Tehran.

\section{Authors' contributions}

All authors equally contributed to preparing this article.

\section{Conflict of interest}

The authors declared no conflict of interests.

\section{Acknowledgments}

The authors would like to appreciate managers and staff of Counseling Centers in Tehran and all participants in the study.

\section{References}

Atkinson, T., \& Perris, P. (2020). Schema Therapy for couples: Interventions to promote secure connections. In G. Heath, \& H. Startup (Eds.), Creative Methods in Schema Therapy (pp. 21024). Milton Park: Routledge. [DOI:10.4324/9781351171847-13]

Bach, P., \& Hayes, S. C. (2002). The use of acceptance and commitment therapy to prevent the rehospitalization of psychotic patients: A randomized controlled trial. Journal of Consulting and Clinical Psychology, 70(5), 1129-39. [DOI:10.1037/0022006X.70.5.1129]

Bach, B., Lockwood, G., \& Young, J. (2018) A new look at the schema therapy model: Organization and role of early maladaptive schemas. Cognitive Behaviour Therapy, 47(4), 328-49. [DOI:10.1080/16506073.2017.1410566] [PMID]

Bond, F. W., \& Bunce, D. (2003). The role of acceptance and job control in mental health, job satisfaction, and work performance. The Journal of Applied Psychology, 88(6), 1057-67 [DOI:10.1037/0021-9010.88.6.1057] [PMID]

Calvete E., Orue I., \& Hankin B. (2013). Early maladaptive schemas and social anxiety in adolescents: The mediating role of anxious automatic thoughts. Journal of Anxiety Disorders, 27(3), 278-88. [DOI:10.1016/j.janxdis.2013.02.011] [PMID]
Dahl, J., Stewart, I., Martell, C., Kaplan, J. S., \& Walser, R. D. (2014). ACT and RFT in relationships: Helping clients deepen intimacy and maintain healthy commitments using acceptance and commitment therapy and relational frame theory. Oakland: New Harbinger Publications. https://www. google.com/books/edition/ACT_RFT_in_Relationships/ SITSNAEACAAJ?hl=en

Descutner, C. J., \& Thelen, M. H. (1991). Development and validation of a Fear-of-Intimacy Scale. Psychological Assessment: A Journal of Consulting and Clinical Psychology, 3(2), 218-25. [DOI:10.1037/1040-3590.3.2.218]

Enright, R. D. (2001). Forgiveness is a choice: A step-by-step process for resolving anger and restoring hope. Washington, DC: American Psychological Association. https://www. google.com/books/edition/Forgiveness_is_a_Choice/ OWN3QgAACAAJ?hl=en

Ehteshamzadeh, P., Ahadi, H., Enayati, M. S., \& Heidari, A (2011). [Construct and validation of a scale for measuring interpersonal forgiveness (Persian)]. Iranian Journal of Psychiatry and Clinical Psychology, 16(4), 443-55. http://ijpcp.iums. ac.ir/article-1-1209-en.html

Fincham, F. D., \& Beach, S. R. (2002). Forgiveness in marriage: Implications for psychological aggression and constructive communication. Personal Relationships, 9(3), 239-51. [DOI:10.1111/1475-6811.00016]

Forman, E. M., \& Herbert, J. D. (2009). New directions in cognitive behavior therapy: Acceptance-based therapies. In W. T. O'Donohue, \& J. E. Fisher (Eds.), General Principles and Empirically Supported Techniques of Cognitive Behavior Therapy (pp. 77-101). New York: John Wiley \& Sons, Inc. https:/ / psycnet. apa.org/record/2009-02305-005

Gehart, D. R. (2012). Mindfulness and acceptance in couple and family therapy. Berlin: Springer. [DOI:10.1007/978-1-4614-3033-9]

Harris, R. (2009). ACT with love: Stop struggling, reconcile differences, and strengthen your relationship with acceptance and commitment. Oakland: New Harbinger Publications. https:// www.google.com/books/edition/ACT_with_=frontcover

Jamalnik, M., Falsafinejad, M. R., \& Khodabakhshi-Koolaee, A. (2020). Long-term marital satisfaction: Couples' narratives of the role of mate selection. Journal of Client-centered Nursing Care, 6(4), 267-76. [DOI:10.32598/JCCNC.6.4.337.1]

Hayes, S. C., \& Wilson, K. (2003). Mindfulness: Method and process. Clinical Psychology: Science and Practice, 10(2), 161-5. [DOI:10.1093/clipsy/bpg018]

Lebow, J. L., Chambers, A. L., Christensen, A., \& Johnson, S. M. (2012). Research on the treatment of couple distress. Journal of Marital and Family Therapy, 38(1), 145-68. [DOI:10.1111/ j.1752-0606.2011.00249.x] [PMID]

Kanter, J. W., Baruch, D. E., \& Gaynor, S. T. (2006). Acceptance and commitment therapy and behavioral activation for the treatment of depression: Description and comparison. The Behavior Analyst, 29(2), 161- 85. [DOI:10.1007/BF03392129] [PMID] [PMCID]

Karakis, E. N., \& Levant, R. F. (2012). Is normative male alexithymia associated with relationship satisfaction, fear of intima$\mathrm{cy}$, and communication quality among men in relationships? 
The Journal of Men's Studies, 20(3), 179-86. [DOI:10.3149/ jms.2003.179]

Khodabakhshi Koolaee, A., \& Hashemi Asl, Z. (2016). [The relationship between fear of intimacy and attachment styles among elderly divorced women (Persian)]. Journal of Prevention and Health, 3, 2. magiran.com/p1552802

Khodabakhshi Koolaee, A., Ahangar, A., Khozani, H. A., \& Hammedy, M. A. (2013). Fear of intimacy and attachment styles in women who apply for divorce. Middle East Journal of Family Medicine, 7(10), 37. [DOI:10.5742/MEJPA.2013.41182]

Körük, S. (2017). Early maladaptive schemas and attachment styles predicting tendencies in intimate relationship. European Journal of Education Studies, 3(9), 393-411. https://www. oapub.org/edu/index.php/ejes/article/view/1028

Montesi, J. L., Conner, B. T., Gordon, E. A., Fauber, R. L., Kim, K. H., \& Heimberg, R. G. (2013). On the relationship among social anxiety, intimacy, sexual communication, and sexual satisfaction in young couples. Archives of Sexual Behavior, 42(1), 81-91. [DOI:10.1007/s10508-012-9929-3] [PMID]

McKay, M., Lev, A., \& Skeen, M. (2012). Acceptance and commitment therapy for interpersonal problems: Using mindfulness, acceptance, and schema awareness to change interpersonal behaviors. Oakland: New Harbinger Publications. https://www. google.com/books/edition/Acceptance_and_een

Najjari, F., Khodabakhshi Koolaee, A., \& Falsafinejad, M., R. (2017). [The effectiveness of group therapy based on Acceptance and Commitment (ACT) on loneliness and psychological adjustment in women after divorce (Persian)]. Journal of Torbat Heydariyeh University of Medical Sciences, 5(3), 68-75. https:/ / www.sid.ir/en/journal/ViewPaper.aspx?id=569302

Nenadić I., Lamberth S., \& Reiss N. (2017). Group schema therapy for personality disorders: A pilot study for implementation in acute psychiatric in-patient settings. Psychiatry Research, 253, 9-12 [DOI:10.1016/j.psychres.2017.01.093] [PMID]

Padgett, E., Mahoney, A., Pargament, K. I., \& DeMaris, A. (2019). Marital sanctification and spiritual intimacy predicting married couples' observed intimacy skills across the transition to parenthood. Religions, 10(3), 177-89. [DOI:10.3390/ rel10030177]

Pananakhonsab, W. (2019). Migration for love? Love and intimacy in marriage migration processes. Emotion, Space, and Society, 31, 86-92. [DOI:10.1016/j.emospa.2019.03.001]

Obeid, S., Sacre, H., Haddad, C., Akel, M., Fares, K., \& Zakhour, M., et al. (2019). Factors associated with fear of intimacy among a representative sample of the Lebanese population The role of depression, social phobia, self-esteem, intimate partner violence, attachment, and maladaptive schemas. Perspectives in Psychiatric Care, 56(3), 486-94. [DOI:10.1111/ ppc.12438] [PMID]

Peterson, B. D., Eifert, G. H., Feingold, T., \& Davidson, S. (2009). Using Acceptance and Commitment Therapy to treat distressed couples: A case study with two couples. Cognitive and Behavioral Practice, 16(4), 430-42. [DOI:10.1016/j.cbpra.2008.12.009]

Roediger, E., Zarbock, G., Frank-Noyon, E., Hinrichs, J., \& Arntz, A. (2020). The effectiveness of imagery work in schema therapy with couples: A clinical experiment comparing the effects of imagery rescripting and cognitive interventions in Brief Schema Couples Therapy. Sexual and Relationship Thera- py, 35(3), 320-37. https://www.tandfonline.com/doi/full/1 0.1080/14681994.2018.1529411

Shirzadi, Z., Khakpour, R., \& Khodabakhshi-Koolaee, A. (2021). The role of attachment styles and spiritual intelligence in predicting women's emotional divorce. Journal of Client-Centered Nursing Care, 7(1), 17-26. https://jccnc.iums.ac.ir/browse. php?a_id $=294 \&$ sid $=1 \&$ slc_lang $=$ en\& $\& \mathrm{ftxt}=0$

Simeone-DiFrancesco, C., Roediger, E., \& Stevens, B. A (2015). Schema therapy with couples: A practitioner's guide to healing relationships. New York: John Wiley \& Sons. [DOI:10.1002/9781118972700]

Spokas, M., Luterek, J. A., \& Heimberg, R. G. (2009). Social anxiety and emotional suppression: The mediating role of beliefs. Journal of Behavior Therapy and Experimental Psychiatry, 40(2), 283-91 [DOI:10.1016/j.jbtep.2008.12.004] [PMID]

Thelen, M. H., Vander, Wal, J. S, Thomas, A. M., \& Harmon, R (2000). Fear of intimacy among dating couples. Behavior Modification, 24(2), 223-40. [DOI:10.1177/0145445500242004] 